\title{
Differences in life satisfaction of elderly people in urban and semi urban families of Lucknow (U.P.)
}

\author{
Priyanka ${ }^{1} \&$ Mishra Sunita ${ }^{2}$ \\ ${ }^{1}$ Assistant professor, Department of Home Science, Khwaja Moinuddin Chishti Urdu, Arabi-Farsi University, \\ Lucknow,India \\ ${ }^{2}$ Professor, School for Home Sciences, Babasaheb Bhimrao Ambedkar University, Lucknow, India
}

\begin{abstract}
The present study was conducted to assess the differences in overall life satisfaction and specific domains of life satisfaction in elderly of urban and semi urban dwellings. The study is based upon sample of 400 elderly (200 urban samples and 200 semi urban samples) of age range 60 years and above 60 years. Life Satisfaction Index for the Third Age-Short Form (LSITA-SF) revised form of Life satisfaction questionnaire developed and standardized by Neogarten (1961)was modified and standardised for Indian elderly for measuring over all life satisfaction and life satisfaction scale developed and standardized by the researcher was used for measuring life satisfaction for specific domains of life satisfaction (health satisfaction, family satisfaction, financial satisfaction, personal satisfaction and social satisfaction). Results revealed that no significant differences were found in overall life satisfaction of elderly people in urban and semi urban dwellings. Significant differences were found in Health satisfaction, Financial satisfaction and Social satisfaction among urban and semi urban elderly.
\end{abstract}

Key words: Elderly life satisfaction, urban and semi urban elderly, specific domain satisfaction.

\section{Introduction}

Aging is common to mankind. Aging is a process which takes place during the entire life span of all organisms. In recent years the science of gerontology and the process of aging have been expanded. This recent interest in aging and the aged stems largely from the fact that the proportion of old people in our society is increasing at a very higher pace. Senior citizens constitute a very vital segment to society. As the world's population ages and people live longer, it is becoming increasingly important to ensure that older people enjoy a good quality of life and experience especially a positive subjective well-being. Satisfaction with life and contributors to well-being in very old age constitute a major concern for the elderly population as well for gerontological research.

Life-satisfaction is one of the indicators of 'apparent' quality of life. Together with indicators of mental and physical health, it indicates how well people thrive. Life-satisfaction is the degree to which a person positively evaluates the overall quality of his/her life as-a-whole. Life satisfaction is the sum totals of perceptions of an individual towards his various aspects of life. Life satisfaction among the elderly is an important concept as it gives us an overall view of the adjustment as well as adaptive coping ability of the individual. The level of satisfaction among the aged effects not only their psychological adjustment but also physical, emotional and social well-being.

Studies on various aspects of social gerontology conducted in India are mostly in the context of urban societies, whereas a larger segment of Indian aged lives in villages. The present study deals with urban as well as village elderly who reside in villages near to city thus having traditional village values but also being affected by nearby city culture. Thus elderly of these semi urban regions have been studied in comparison to elderly of urban region or the city.

\subsection{Sample:}

\section{Methodology}

The sample consists of 400 elderly of age group 60 and above 60 years who were selected randomly from different colonies and villages of three tehsils and eight community development blocks of Lucknow district, Uttar Pradesh.

\subsection{Tools Used:}

Life Satisfaction Index for the Third Age-Short Form (LSITA-SF) revised form of Life satisfaction questionnaire developed and standardized by Neogarten (1961) was modified and standardised for Indian elderly and used for measuring over all life satisfaction of elderly people. 
Life satisfaction scale for specific domains developed and standardized by researcher (2009) was used for measuring life satisfaction for specific domains of elderly people.

\subsection{Procedure:}

Along with the Life satisfaction scale for specific domains and Life Satisfaction Index for the Third Age-Short Form (LSITA-SF), an interview schedule was developed by investigator to collect general information. After administration of these tools, collected data was scored and analysed statistically using ANOVA.

\section{Observations And Discussions}

To find out the mean differences in life satisfaction of urban elderly and semi urban elderly ANOVA test was done.

\subsection{Health Satisfaction}

\begin{tabular}{|c|c|c|c|c|c|c|}
\hline \multirow[t]{2}{*}{ S.No. } & \multirow{2}{*}{$\begin{array}{l}\text { LIFE SATISFACTION } \\
\text { OF ELDERLY }\end{array}$} & \multicolumn{2}{|c|}{ URBAN ELDERLY } & \multicolumn{2}{|c|}{$\begin{array}{l}\text { SEMI URBAN } \\
\text { ELDERLY }\end{array}$} & \multirow[t]{2}{*}{ F' Value } \\
\hline & & Mean & S.D & Mean & S.D. & \\
\hline 1 & Health satisfaction & 7.2500 & 2.3766 & 6.3667 & 2.0990 & $7.4288 * *$ \\
\hline 2 & Financial satisfaction & 5.6333 & 2.1860 & 7.7000 & 1.8983 & $\begin{array}{l}39.9895 * \\
*\end{array}$ \\
\hline 3 & Family satisfaction & 7.2500 & 2.7533 & 7.1333 & 2.7051 & $\begin{array}{l}2.4251 \\
\text { NS }\end{array}$ \\
\hline 4 & Personal satisfaction & 6.2333 & 2.0283 & 6.9167 & 2.6826 & $\begin{array}{l}2.3333 \\
\text { NS }\end{array}$ \\
\hline 5 & Social satisfaction & 6.8333 & 2.6099 & 8.2000 & 2.1376 & $7.9885 * *$ \\
\hline 7 & $\begin{array}{l}\text { Over life } \\
\text { satisfaction }\end{array}$ & 7.7333 & 2.0656 & 7.5667 & 2.0615 & $\begin{array}{l}1.1072 \\
\text { NS }\end{array}$ \\
\hline
\end{tabular}

The information in the above table indicates that there were significant differences between urban elderly and semi urban elderly in health satisfaction. Urban elderly reported higher mean score than semi urban elderly in health satisfaction. This could be because health leads to a number of problems among aged. Physical impairment of vision and hearing reduces the mobility and interaction of the elderly. This results in feeling of loneliness and isolation. The onset of diseases one after other due to slow degradation of body starts lowering one's life satisfaction. As people age, health related problems increase and life quality decreases since health affects all aspects of life, including participation in social life, income, level of mobility, and dependency. Though this aging affect is universal a no. of facilities and specialized services in medical field is available in urban cities. Thus there is a better platform to fight with aging health problems by urban elderly compared to semi urban and rural are as which are devoid of these facilities.

In rural areas, the health of older persons may be particularly influenced by poverty, which are often life-long, lack of education (especially for women), poor nutrition, and increased risk of accidents. The primary care of the elderly is provided by Primary-HealthCare teams in towns and villages. For a high proportion of rural elderly, these services are deficient or not readily accessible, and even when they are accessible the staff often lack training in the care of older people. After visiting a doctor or medical person not only ones objective health but a psychological affect is seen that I am being cared and under supervision thus elders after this may rate themselves better. While semi urban elderly devoid of these checkups may perceive them ill and that finally affects life satisfaction. For example, (Berg et al. 2006), using data from the European Study of Ageing Well 2001/02 for 522 Swedish individuals aged 65-89 with reduced self-care capacity, found that poor overall self-reported health had the strongest explanatory power for life satisfaction.

\subsection{Financial satisfaction}

There were significant differences between urban elderly and semi urban elderly in financial satisfaction. Urban elderly reported higher mean score than semi urban elderly in financial satisfaction. Social adjustment of the elderly in India to a great extent is dependent on their economic condition that can be gauged by their employment status or their income. Elderly not only are forced to survive with no income or diminished income, but also retirement from regular employment, which was a source of identity for them for a long period of time, has damaging impact on the personality of the elderly. Suddenly they are expected to do away with their identity and social status through which they used to relate themselves with 
the society. Due to economic reforms urban elderly have got better prospective as pension, working in informal sectors and some have options in even formal sectors. In urban areas elderly also have plans for future and can engage themselves in that. Whereas in rural and semi urban areas generally stricken by poverty, get more financially dependent and week comparing to urban elderly. (Revicki \& Mitchell, 1990) found financial satisfaction measured as the perception of economic deprivation has been found to be related to lower satisfaction with life, therefore, financial security seems to constitute an important component of life satisfaction in old age. Although well-being does not increase with more money to spend, the experience of financial insecurity probably represents a basic menace to life satisfaction even in old age.

\subsection{Family satisfaction}

There were no significant differences between urban elderly and semi urban elderly in family satisfaction. This could be because elderly in either the dwellings of urban or semi urban have family problems due to present globalized changes that have shaken old Indian family structure and system. For Since time immemorial the joint family has been one of the salient features of the Indian society. But the twentieth century brought enormous changes in the family system. Changes in the traditional family system have been so enormous that it is steadily on the wane from the urban scene. The adults have migrated to cities from rural and semi urban areas either to pursue higher education or to secure more lucrative jobs or to eke out their living outside their traditional callings, ensuing from the availability of better opportunities elsewhere as well as the rising pressure of population on the limited land base. Many of the urban households are really off shoots of rural extended or joint families. Thus in semi urban areas due to migration elderly are left alone or segmented. Also, migration affects the capacity of rural families to care for their elders or for urban children to support aging parents left in semi urban areas. Whereas in urban areas even if elderly are living with their children, working of both men and women and their grandkids busy in their own daily schooling and activities leaves elderly isolated and lonely.

A recent study by (Okoye2004) explored how Nigerian youths feel about care-giving for the elderly and their views about traditional ways of taking care of the elderly. She observed in her study that the youngsters are not willing to live with their aged parents; neither they were willing to send their wife nor their children to the village to live with their aged parents. An earlier work examined the link between social support/networks, urban condition and physical wellbeing of the elderly (Asiyanbola, 2004).

(Patil, P. B.) carried out study in Dharwad district, Karnataka with a sample of 220 elderly persons. The results revealed a positive and significant relationship between family solidarity and life satisfaction of the elderly i.e good family solidarity improved the life satisfaction of the elderly and poor family solidarity reduced the life satisfaction of the elderly.

\subsection{Personal satisfaction}

There were no significant differences between urban elderly and semi urban elderly in personal satisfaction. This could be because one's ability to successfully age is determined to a great extent by their attitudes toward aging and growing old. These positive and negative attitudes will be the result of how effectively an individual is able to adapt to the physical, psychological, and social changes that will take place throughout adulthood. In our society as a whole either urban or semi urban region, not very friendly and empathetic attitude prevails towards elderly. Thus elderly should be counseled and encouraged to intervene and introspect their attitude and perception so that feel high personal satisfaction that in turn would enhance their life satisfaction. If someone is able to accept the changes of life and look forward to the challenges that they present with hope and desire to change, then they will be better prepared to face old age. People who believe in their ability will set higher goals for themselves and expect that they will be able to achieve these goals. Self-efficacy has been found to influence the adaptive strategies used by older adults (Slangen-DeKort, 2001).

\subsection{Social satisfaction}

There were significant differences between urban elderly and semi urban elderly in social satisfaction. Semi Urban elderly reported higher mean score than urban elderly in social satisfaction. This could be because still in semi urban region people especially neighbors and 
community members due to less globalization and urbanization are in touch and united. Whereas in cities people are hardly bothered about each other as are busy in their own lives. Even family members are highly engaged in their lifestyles with lots of generation gaps in different spheres of life and way of thinking. Thus even being in family elders may feel segregated and lonely. Social relationships and social support systems serve as protective factors in many ways. They benefit individuals by enhancing self-esteem, providing encouragement, and promoting healthy behaviors. It is also possible that social networks may provide more tangible assistance such as food, clothing, and transportation. This type of assistance enables an elderly person to remain socially active even though they may not have the means to do so on their own. It is also important to distinguish the difference between receiving support and assistance from friends or relatives as opposed to agency assistance. Possibly the most important source of social support comes from the family, which provides self-system mechanisms which increase an individual's subjective impression of life satisfaction. In addition families provide a system of support and interaction that may not be available from outside sources for some elderly people. All of these types of networks may prevent the degree of social isolation in old age that is associated with depression and other psychological problems. Thus semi urban elderly may have better opportunity of family members and friends who are available for them and spend more quantity and quality of time. This provides them better support system than urban elderly.

Much research has focused on that aspect of social stability which is measured by the number and the relative strengths of the various elements of social support (Bahr and Garrett, 1976). (Moriwaki1973) has identified the importance of the presence of social support to feelings of well-being among the elderly.

\subsection{Overall life satisfaction}

There were no significant differences between urban elderly and semi urban elderly in overall life satisfaction. This could be because different domains of life have different affect on life satisfaction. Urban elderly may have good health and financial satisfaction whereas semi urban elderly were better in personal and social satisfaction. Thus elderly in both dwelling have their own issues and challenges resulting not much difference in their overall life satisfaction.

\section{Conclusion}

The study adds to the necessity of research in gerontology which is the need of hour as with the rapid increase in elderly population of India it's the forthcoming challenge for the nation. The present research however dispels that the condition of elderly on a whole is not satisfactory for elderly either in village families or city families. The urban elderly reported better health and financial satisfaction because of good health facilities due to advanced hospitals and other urbanized sectors for reemployment and some source of earning money. In semi urban regions neither proper health nor re-employment facilities were available neither the familial and social bonding of traditional times due to urbanization. Nor they have traditional occupation as farming and children have fled to nearby city for earning leaving them alone and isolated. The study had shown significant differences among urban and semi urban elderly in health satisfaction, financial satisfaction and social satisfaction. Ensuring good quality geriatric health care services at the primary level would greatly help in improving the utilization rates of the available health services. Health care services should be based on the "felt needs" of the elderly population especially rural and semi urban areas. Their ability to lead healthy and fruitful lives should be ensured by the Government. Financial support and upliftment is highly needed for semi-rural elderly as this would improve their life satisfaction. The elderly should be considered as human resources and their rich experience and residual capacities should be put to optimum use for the benefit of national development. Although well-being does not increase with more money to spend, the experience of financial insecurity probably represents a basic menace to life satisfaction even in old age. Even though urban elderly have better medical and financial facilities but had reported low in social satisfaction. With urbanization and globalization the traditional family structure is deteriorating continuously. Social pressure continues to be placed on persons who fail to discharge this responsibility to their elderly family members. Thus it is important to strengthen these values and the capacity of families to cope with the problems of caring for the elderly. Since a culture of both working partners is on rise so there is an immediate need for developing such systems and options where urban elderly can interact, enjoy and develop social relations to satisfy their intense need for proper socialization. Thus elderly in both the dwellings have their own problems and issues which needs to be addressed accordingly. 


\section{References}

[1]. Neugarten, B., Havighurst, L., \& Tobin, S. (1961). The measurement of life satisfaction. Journal of Gerontology, 16, $134-143$.

[2]. Berg, A.I., Hassing, L.B., MCClearn, G.E. \& Johansson, B. (2006). What Matters for Life Satisfaction in the Oldest-old? In: Aging \& Mental Health, 10(3), 257-264.

[3]. Revicki, D. A., \& Mitchell, J. P. (1990). Strain, social support, and mental health in rural elderly individuals. Journal of Gerontology, 45(6), S267-274.

[4]. OkoyeUzomaOdera (2004) "The erosion of traditional forms of care for the elderly and its implication for the elderly in Nigeria" A paper presented at the International Conference on "Rapid Ageing and the changing role of the elderly in African households", Organized by the Union for African Population Studies UAPS/UEPA (Senegal), the HSRC in collaboration with the Department of Social Development (South Africa) 18-20 August, 2004, Pretoria, South Africa.

[5]. Asiyanbola R. A. (2004) "Social support/networks, urban condition and physical well being of the elderly in Africa: a preliminary survey in Ibadan, Nigeria" A paper presented at the International Conference on "Rapid Ageing and the changing role of the elderly in African households", Organized by the Union for African Population Studies UAPS/UEPA (Senegal), the HSRC in collaboration with the Department of Social Development (South Africa) 18-20 August, 2004, Pretoria, South Africa.

[6]. Patil, P. B.; Yadav, V. S.; Gaonkar, V. 2009 Influence of family solidarity on life satisfaction of the elderly, Journal of Dairying, Foods and Home Sciences, 28: 2, 149-151.

[7]. Slangen-Dekort, Y.A. W., Midden, J.B.C., Aarts, B., Wagenberg, F.V., (2001). Determinants of adaptive behavior among older persons: Self-efficacy, importance, and personal disposition as directive mechauisms. International Journal of Aging and Human Development, 53(4),253-274.

[8]. Bahr, Howard M. and Gerald R. Garrett 1976 Women Alone: The Disaffiliation of Urban Females. Lexington, Mass.: D. C. Heath and Company.

[9]. Moriwaki, Sha r on 1973 "Self-disclosure, significant others and psychological well-being in old age." Journal of Health and Social Behavior 14: 226-232. 